\title{
RANCANG BANGUN PROTOKOL PERUTEAN SDGR+R PADA VEHICULAR AD- HOC NETWORK BERBASIS ARAH
}

\author{
Eliyah Acantha Manapa*1, Sri Wahjuni², Shelvie Nidya Neyman ${ }^{3}$ \\ 1,2,3 Jurusan Ilmu Komputer, Fakultas Matematika dan Ilmu Pengetahuan Alam, Institut Pertanian Bogor \\ Email: ${ }^{1}$ acantha_19@apps.ipb.ac.id, ${ }^{2}$ my_juni04@apps.ipb.ac.id, ${ }^{3}$ shelvie@apps.ipb.ac.id \\ *Penulis Korespondensi
}

(Naskah masuk: 21 Desember 2019, diterima untuk diterbitkan: 26 November 2020)

\begin{abstract}
Abstrak
Vehicular Ad-Hoc Network (VANET) merupakan pengembangan jaringan wiresless yang melakukan komunikasi secara Inter Vehicle Communication (IVC). VANET memiliki mobilitas yang tinggi untuk setiap node nya sehingga jaringan komunikasi jenis ini adalah jaringan yang bersifat sementara dikarenakan node bergerak di lintasan dengan arah dan kecepatan yang dinamis. Dengan demikian, pengiriman paket data dari node sumber ke node tujuan menggunakan VANET memerlukan beberapa teknik komunikasi. Teknik terbaru komunikasi VANET saat ini adalah menggunakan SDN (Software Defined Network) yang berbasis geographic (SDGR) sebagai control plane dalam mengontrol komunikasi ad-hoc antar node. Dalam membentuk topologi jaringan komunikasi, SDGR mencari nilai jalur terpendek antar node dan kepadatan node yang tinggi. Tujuan utama penelitian ini melakukan analisis konsep protokol perutean (routing protocol) SDGR dan dilakukan pengembangannya dengan mempertimbangkan arah rute $(\mathrm{SDGR}+\mathrm{R})$. Pada $\mathrm{SDGR}+\mathrm{R}$, penambahan basis arah rute menggunakan multicast. Selanjutnya, dilakukan perbandingan kinerja antara SDGR dan SDGR+R. Hasil simulasi menunjukkan SDGR $+\mathrm{R}$ memiliki kinerja lebih baik daripada SDGR dalam hal latency sebesar $1.88 \%$ dan packet delivery ratio (PDR) sebesar $8.12 \%$. Perancangan protokol perutean $\mathrm{SDGR}+\mathrm{R}$ menambah ide pengembangan teknologi pada VANET untuk masa mendatang.
\end{abstract}

Kata kunci: vanet, software defined network, protocol routing, multicast, latency, packet delivery ratio

\section{SDGR+R: A ROUTING PROTOCOL FOR VEHICULAR AD HOC NETWORK BASED ON DIRECTION}

\begin{abstract}
Vehicular Ad-Hoc Network (VANET) is a wireless network developed for communication on Inter-Vehicle Communication (IVC). Each node in a VANET has high mobility so that this type of communication network is a temporary network because the node moves on the track with dynamic direction and speed. Thus, sending data packets from source node to destination node using VANET requires some communication techniques. The latest technology for VANET communication is to use SDN-based geographic-based SDN (SDGR) as a control plane in controlling Ad-hoc communication between nodes. In forming the communication network topology, SDGR looks for the shortest path value between nodes and high node density. The main objective of this research is to analyze the concept of SDGR routing protocol and to develop it, considering the direction of the route (SDGR $+R)$. In $S D G R+R$, the addition of route base directions uses multicast. Next, we compare the performance between SDGR and $S D G R+R$. Simulation results show $S D G R+R$ has better performance than SDGR in terms of latency of $1.88 \%$ and packet delivery ratio of $8.12 \%$. The design of the $S D G R+R$ routing protocol gives to the idea of technology development on VANET in the future.
\end{abstract}

Keywords: vanet, software defined network, routing protocols, multicast, latency, packet delivery ratio

\section{PENDAHULUAN}

Jaringan nirkabel dibedakan menjadi dua yaitu jaringan nirkabel dengan infrastruktur dan jaringan nirkabel tanpa infrastruktur. Jaringan nirkabel dengan infrastruktur adalah jaringan yang menggunakan access point sebagai pusat kendali (central controller), sedangkan jaringan nirkabel tanpa infrastruktur adalah jaringan yang tidak memerlukan access point untuk dapat saling berkomunikasi antara satu perangkat dengan perangkat lainnya (Zeadally, et al., 2012). Komunikasi pada jaringan non infrastruktur dilakukan secara langsung antara satu simpul (node) dengan simpul lainnya melalui suatu 
sistem yang disebut jaringan ad hoc. Jaringan ad hoc yang memiliki simpul bergerak dengan posisi yang berubah secara dinamis dikenal dengan istilah MANET (Mobile Ad Hoc Network) (Dewi, et al., 2016).

Pada pengembangan selanjutnya, MANET untuk node yang memiliki pergerakan cepat pada lintasan jalan yang dilalui disebut VANET (Verhicular Ad Hoc Network) (Dewi, et al., 2016). VANET memungkinkan komunikasi antar kendaraan tanpa infrastruktur pada suatu lingkup area dalam jarak $100-500$ meter. Terdapat tiga jenis model komunikasi di dalam sistem VANET, yakni (1) intervehicle yaitu komunikasi antar vehicle, (2) vehicle to roadside yaitu komunikasi vehicle dengan roadside unit, (3) inter-roadside yaitu komunikasi antara roadside dengan base station (Pradana, et al., 2017).

VANET memiliki routing protocol untuk saling berkomunikasi mempertukarkan data satu sama lain. Routing protocol yang umum digunakan yakni AODV (Ad Hoc On Demand Vector) dan GSPR (Greedy Primeter Stateless Routing) (Ji, et al., 2016). Selain kedua routing protocol tersebut, saat ini telah berkembang paradigma baru dalam mengontrol jaringan yang memisahkan antara data-plane dan control-plane pada perangkat jaringan yang disebut SDN (Software Defined Network) (Ku, et al., 2014). Penerapan SDN pada VANET diusulkan pertama kali oleh Zhu et al. (2015).

Liu et al. (2015) mengusulkan arsitektur SDN untuk perutean GeoBroadcast di VANET dengan menambahkan komponen manajemen RSU secara otomatis. GeoBroadcast dalam jaringan VANET mendukung pesan secara berkala dari node sumber ke node destinasi yang terletak di wilayah geografis tertentu. Konsep SDN terhadap VANET adalah untuk mengetahui lokasi node kendaraan, kepadatan kendaraan dan peta digital secara umum (He, et al., 2016). SDN berfungsi sebagai pengontrol pusat dalam mengumpulkan informasi node yang terkoneksi dengan jaringan switch atau RSU (Road side unit), dan menghitung jalur routing optimal untuk node berdasarkan informasi yang diperoleh dari RSU (Zhu, et al., 2015).

Paradigma SDN ini dicoba pada teknologi VANET dengan GeoBroadcast guna meningkatkan beberapa kinerja (Liu, et al., 2015). Penelitian berikutnya mengusulkan SDGR (SDN-based Geographic Routing Protocol) dan dibandingkan dengan AODV dan GSPR (Ji, et al., 2016). Hasil simulasi menunjukkan bahwa metode SDGR mendapatkan kinerja lebih baik dibandingkan AODV dan GSPR dalam packet delivery ratio (PDR) dan latency. Adaptasi metode SDN sebagai pusat kontrol pada VANET dalam SDGR dapat menampilkan keadaan di jalan secara menyeluruh seperti mekanisme deteksi kepadatan node yang memainkan peran penting dalam keseimbangan beban untuk node, serta mengurangi packet loss ratio dan delay transmisi lebih efektif.

Selama ini belum ada penelitian yang melibatkan arah pergerakan node dalam mempertimbangkan rute pada penggunaan SDGR pada VANET, sehingga topik penelitian ini adalah pengembangan routing protocol SDGR dengan berbasis pergerakan node dan arah rute (SDGR+R). Hasil penelitian ini diharapkan mampu meningkatkan kinerja pada VANET khususnya implementasi pada penentuan rute untuk packet yang akan dikirim ke sebuah node.

Berkenaan hal tersebut digunakan ide Local computation based on intersection (Noorani \& Seno, 2018) untuk mendukung perhitungan transmisi range komunikasi dari antar setiap node. Sementara untuk mengetahui range (jarak) antar node konsep yang digunakan adalah source within communications range (Ghafoor \& Koo, 2018). Kedua konsep tersebut adalah menggunakan teknik multicast. Multicast adalah teknik komunikasi one-to-many yang artinya sebuah data dikirimkan oleh node ke beberapa node dalam grup tertentu. Penentuan grup multicast yang digunakan pada penelitian ini adalah arah rute sebuah node. Berdasarkan hal tersebut, maka secara otomatis komunikasi pengiriman paket antar node mempertimbangkan arah rute sebuah node yang masih dalam area node tersebut.

\section{METODE PENELITIAN}

Penelitian dilakukan melalui beberapa tahapan yaitu, analisis algoritma SDGR, perancangan algoritma SDGR berbasis Rute (SDGR+R), perancangan proses simulasi, konfigurasi mobilitas, konfigurasi NS, pengambilan data, membandingkan parameter terkait, dan evaluasi. Tahapan alur penelitian ini dapat dilihat pada Gambar 3.

\subsection{Konsep SDGR Basis Rute (SDGR+R)}

Pada $\mathrm{SDGR}+\mathrm{R}$, node untuk membentuk jalur pengiriman dan penerusan paket data dari node sumber ke node tujuan yang diutamakan adalah memiliki jalur rute yang sama. Setiap kendaraan (node) diberitahu tentang situasi tetangganya, selanjutnya paket data ditransmisikan melalui komunikasi V2V ke node yang memiliki rute yang searah. Pada Gambar 1 rancangan penelitian menggunakan dua buah konsep dasar dalam tahap proses simulasi. Dari data evaluasi yang diperoleh, bila terdapat perbedaan akan dilanjutkan dengan evaluasi dan penarikan kesimpulan.

$\mathrm{SDGR}+\mathrm{R}$ dilakukan penambahan algoritma ip_dest sameroute dengan konsep multicast, dengan tujuan agar node melakukan penerusan paket terhadap node yang sejalur. Sebagai contoh apabila node a masuk dalam range node $\mathrm{b}$, maka node a masuk dalam tabel connectivitylist node b sehingga dapat saling berhubungan. 


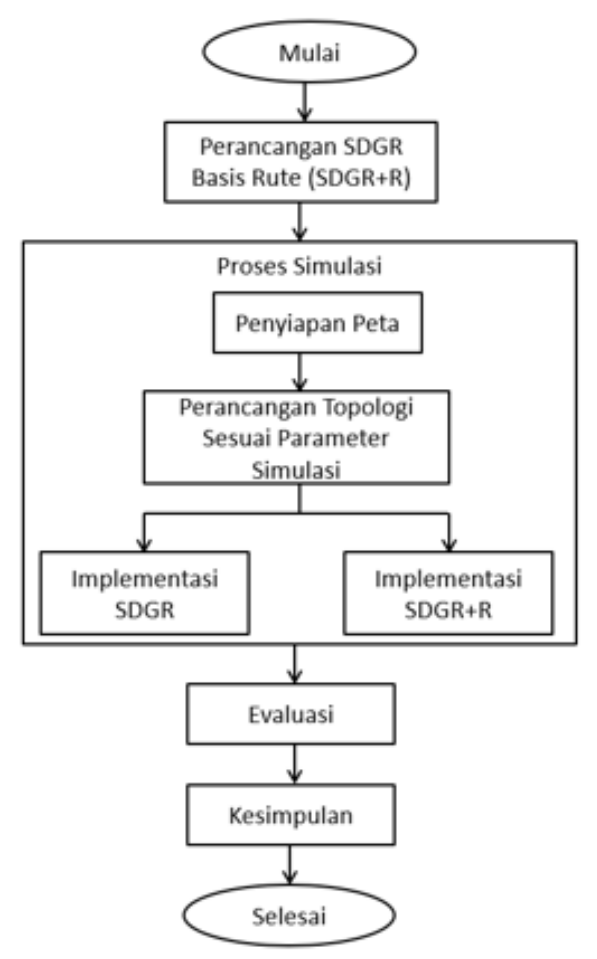

Gambar 1. Tahapan penelitian

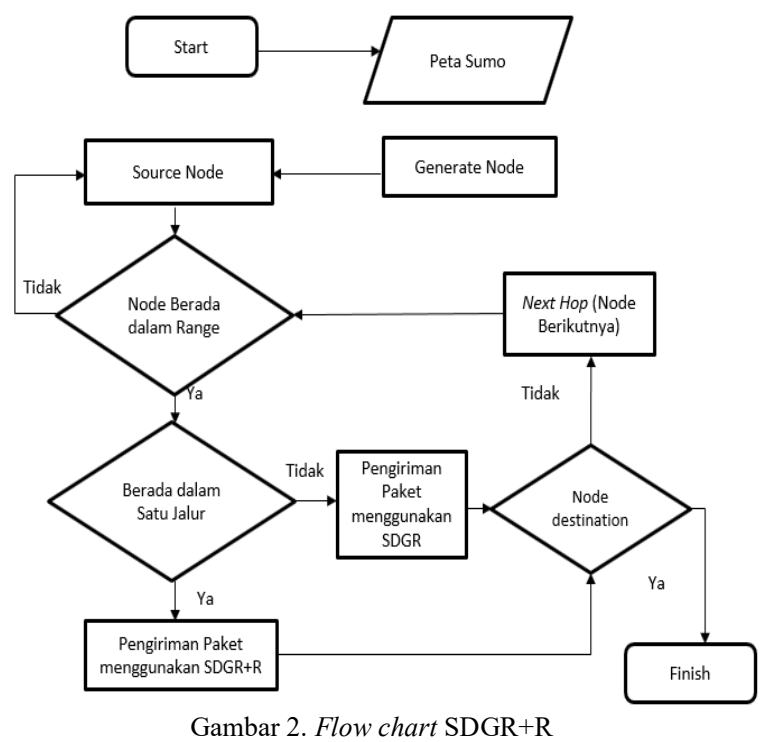

Gambar 2. Flow chart $\mathrm{SDGR}+\mathrm{R}$

Algoritma arah rute di SDGR $+\mathrm{R}$ menggunakan informasi titik kemunculan node dan range connectivity node menggunakan tinjauan global yang disediakan oleh SDN, selanjutnya dapat mempertimbangkan rute node dengan kepadatan kendaraan tinggi. Multicast adalah metode perutean data pada jaringan yang memungkinkan node tunggal atau sekelompok node untuk berkomunikasi secara efisien dengan node receiver (Kadhim \& Seno, 2019). Multicast mendukung one-to-many routing dalam satu perangkat (node) mengirimkan data ke sekelompok node. Selain itu, multicast juga mendukung routing many-to-many. Sebagai contohnya, apabila node a (source) ingin mengirim data ke node x (destination). Node tersebut mencari jarak terdekat dari node a ke node $\mathrm{x}$ yang dapat dilalui dalam pengiriman paket data. Sehingga akan terbentuk topologi komunikasi dari node $\mathrm{a}-$ node $\mathrm{b}$ node $\mathrm{c}$ - node $\mathrm{x}$ seperti Gambar 3 .
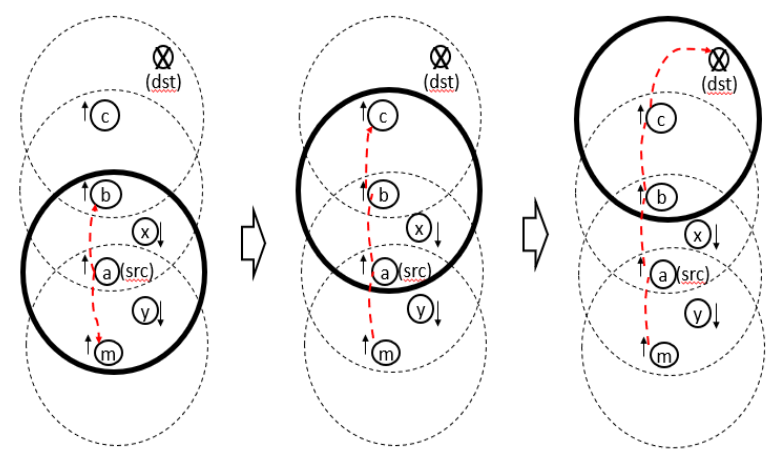

Gambar 3. Prinsip pengiriman paket antar node pada SDGR $+\mathrm{R}$

Pada Gambar 4 ditujukkan jika terdapat node c dan node $\mathrm{b}$ dalam jangkauan range transmisi node a, dan jarak terdekat node a adalah node c, dan diketahui bahwa node $\mathrm{b}$ ini dekat dengan node $\mathrm{x}$ sebagai destination, maka node a langsung berkomunikasi dengan node $\mathrm{b}$ tanpa perlu melalui node $\mathrm{c}$.

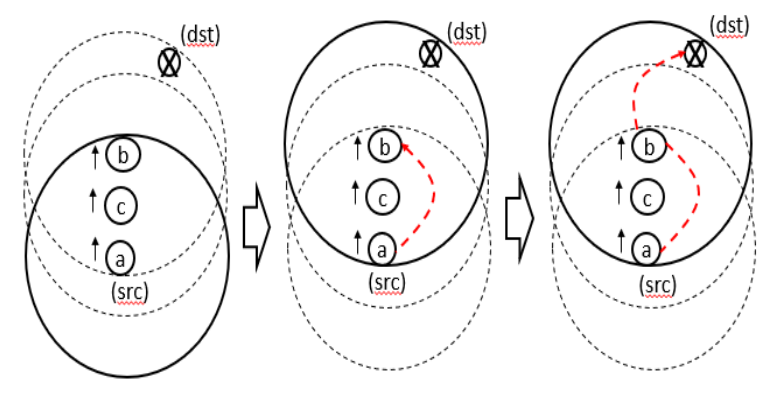

Gambar 4. Prinsip penerusan paket antar node pada $\mathrm{SDGR}+\mathrm{R}$

\subsection{Topologi SDGR dan SDGR+R}

Konsep ofp pada SDGR adalah menghitung jumlah kendaraan yakni nodes secara langsung termasuk posisi nya, kecepatan dan arah, src adalah kendaraan sumber, dest adalah kendaraan tujuan. Node sumber ( $s r c)$ berkomunikasi dengan node tujuan $(d s t)$ dapat dilihat pada Gambar 5. Kelemahan dari SDGR adalah jika terjadi delay dan perubahan topologi, hasil ofp pada tabel routing terlambat untuk diperbaharui.

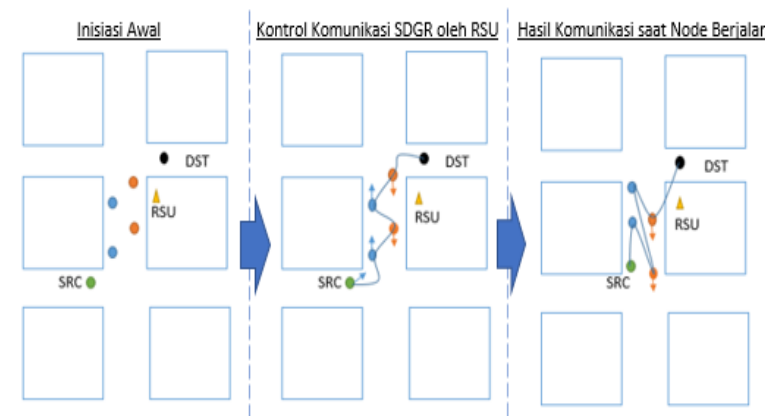

Gambar 5. Konsep dasar SDGR 
Pada konsep SDGR+R dilakukan penambahan atribut berupa arah rute pada node untuk menentukan next-hop. Jadi pembentukan jalur antar node dilakukan dengan mempertimbangkan rute yang searah dan node tersebut berada dalam jangkauan transmisi. Dengan demikian, diharapkan komunikasi antara node src dengan node dest akan lebih efektif tanpa harus berganti topologi (Gambar 6).

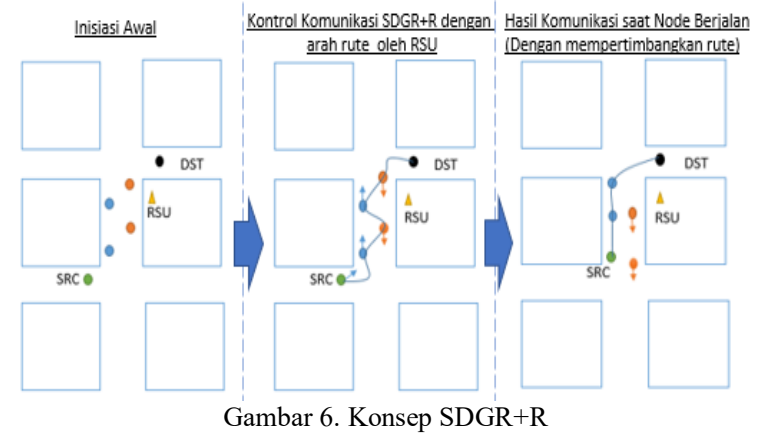

\section{SDN-BASED GEOGRAPHIC ROUTING}

SDN controller terkoneksi dengan internet untuk mengatur VANET, dalam berbagai hal yakni routing, access control dan flow control (Zhu, et al., 2015). Pemanfaatan SDN oleh kendaraan menggunakan road side units (RSU) dan base station untuk mengirim pesan kontrol dan menggunakan komunikasi vehicle-to-vehicle (V2V) dalam meneruskan data (Ji, et al., 2016). Desain arsitektur SDN-based geographic (SDGR) pada VANET dapat dilihat pada Gambar 7.

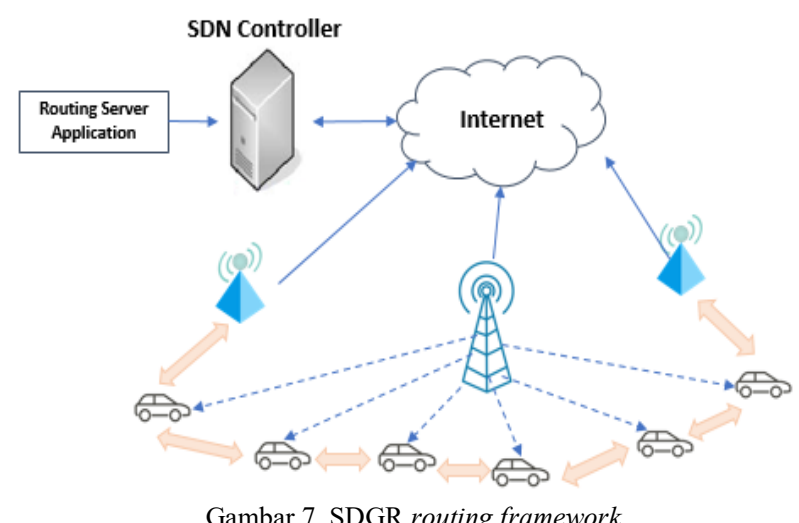

SDGR adalah routing protocol berbasis geografis yang diusulkan untuk VANET dengan menggetahui lokasi node dan kepadatan kendaraan pada peta digital. Algoritma inti pada SDGR yakni optimal forwading path algorithm (ofp) dan packet forwarding algorithm.

Pada SDGR, setiap client memperbaharui informasi secara berkala dari lokasi dan kecepatan kendaraan saat ini dengan mengirimkan pesan status terbaru ke server routing (SDN). Informasi lokasi dan kecepatan dikumpulkan oleh perangkat GPS kendaraan dan sensor kecepatan kendaraan. Setelah menerima status pesan terbaru, SDN akan memperbaharui status jaringan pada kendaraan tersebut. Berikut ini adalah pseudo code dari SDGR (Ji, et al., 2016).

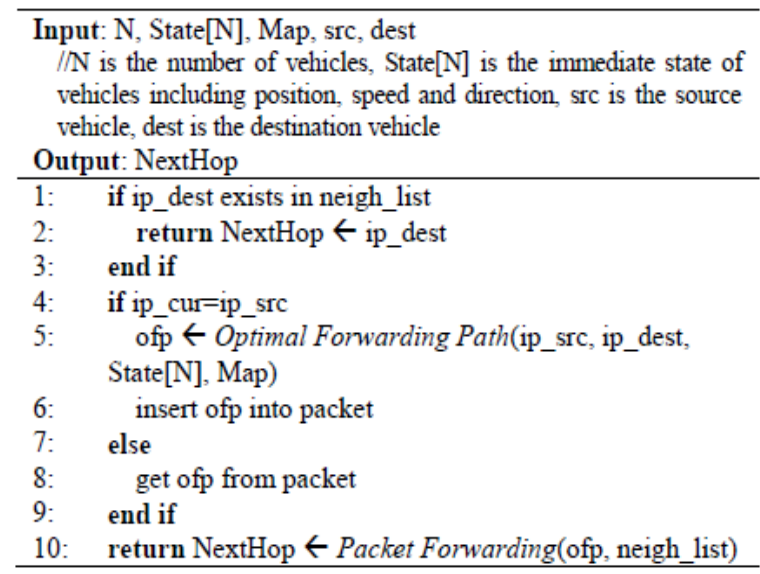

Ketika sebuah node sumber memiliki paket untuk dikirim, pertama-tama routing akan memeriksa apakah node tujuannya ada dalam table routing atau tidak. Jika ada, klien routing akan mengirimkan paket ke tujuan secara langsung. Setelah menerima pesan permintaan, SDN akan memanggil algoritma ofp untuk menghitung jalur pengiriman paket dari node sumber ke node tujuan. Hal ini dilakukan untuk memilih next-hop berikutnya yang ideal sampai paket mencapai tujuan.

Gagasan utama dari optimal forwarding path (ofp) adalah menemukan urutan persimpangan dari node sumber ke node tujuan dengan panjang jalan yang lebih pendek dan kepadatan yang lebih tinggi. Algoritma ofp akan membentuk jalur penerusan paket data dari node sumber ke node tujuan dengan cara mengecek panjang jalan dan kepadatan kendaraan. Algoritma Dijkstra diterapkan untuk menemukan jalur terpendek dengan bobot minimum optimal path (Lin, et al., 2015).

Struktur VANET dapat dianggap sebagai graph undirected $\mathrm{D}=(\mathrm{V}, \mathrm{E})$, dimana $\mathrm{V}$ adalah satu set persimpangan dan $\mathrm{E}$ adalah seperangkat jalan raya. Fungsi metrik ofp menggabungkan kendaraan dan panjang jalan diusulkan oleh Lin et al. (2015). Nilai bobot setiap jalur $\left(\mathrm{w}_{\mathrm{ri}}\right)$ didefinisikan pada Persamaan $(1 ; 2)$.

$w_{r_{i}}=\beta * f\left(L_{r_{i}}\right)+\frac{\gamma}{g\left(T_{r_{i}}\right)}$

$\mathrm{T}_{r i}$ adalah kepadatan kendaraan

$\mathrm{L}_{\mathrm{ri}}$ adalah panjang jalan yang menghubungkan dua persimpangan.

Nilai $\beta$ dan $\gamma$ adalah faktor konstan.

$W_{k}=\sum w_{r_{i}},(k=1,2, \ldots, m)$

$\mathrm{W}_{\mathrm{k}}$ adalah jumlah total nilai bobot setiap jalur

$m$ adalah angka dari semua potensi jalur penerusan paket dari node sumber ke node tujuan

Jika hasil nilai bobot setiap jalur tidak unik, selanjutnya menggunakan hitungan derivasi setiap 
jalur lalu memilih jalur terendah sebagai jalur optimal forwarding path dengan Persamaan (3; 4).

$$
\sigma_{k}=\sqrt{\frac{1}{N} \sum\left(T_{p_{i}}-\mu_{k}\right)^{2}}
$$

$\mu_{k}=\frac{1}{N} \sum T_{p_{i}}$

$\mathrm{N}$ adalah jumlah jalan raya yang terdapat pada jalur penerusan paket.

Penentuan jalur penerusan ( $o f p$ ) dengan memilih nilai $\mathrm{W}_{\mathrm{k}}$ yang minimum dan $\sigma_{k}$ yang kecil. Algoritma ofp juga mempertimbangkan kepadatan kendaraan di setiap jalan untuk menghindari sparse connectivity dimana node akan sulit saling berkomunikasi karena jarak yang jauh antar node karena lebih sedikit jumlahnya. Sebagai contohnya dapat dilihat pada Gambar 8.

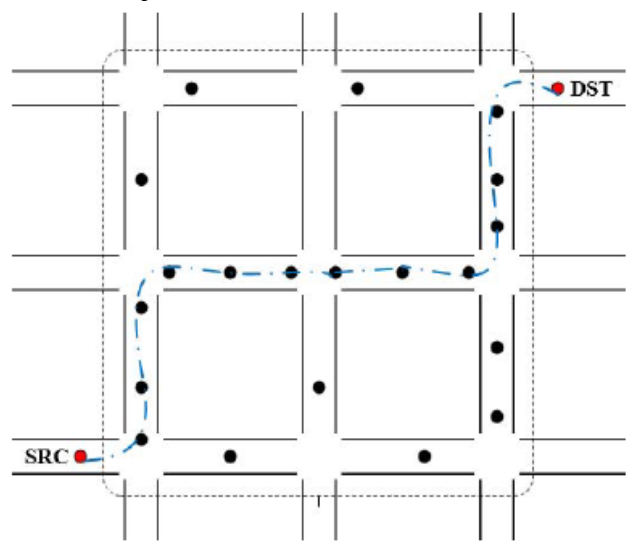

Gambar 8. Optimal forwarding path (Ji, et al., 2016)

Setelah node sumber mengetahui jalur untuk mengirim paket ke node, langkah selanjutnya adalah algoritma packet forwarding untuk next-hop berikutnya dalam proses pengiriman paket. Nodes (Kendaraan) memperoleh informasi mobilitas satu sama lain dengan mengirim paket 'hello' untuk handshaking. Terdapat dua bagian packet forward yakni forthright mode dan junction mode. Pada forthright mode, client routing memilih paket nexthop untuk meneruskan paket dengan informasi sesuai nilai jalur ofp yang didapatkan. Jika nilai ofp sama, maka junction mode diterapkan pada mekanisme deteksi kemacetan dalam memilih node yang tepat dalam melakukan broadcast jaringannya.

\section{HASIL DAN PEMBAHASAN}

\subsection{Data Penelitian}

Data dalam penelitian ini berupa peta angkutan umum kota Bogor di sekitar Stasiun Kereta Api Bogor yang diambil dari OpenStreetMap (OSM) (Gambar 9). Peta rute yang didapat dari OSM dijadikan peta digital menggunakan tools Simulation of Urban Mobility (SUMO) untuk mobility generator yang digunakan pada simulasi VANET (Gambar 10). Hasilnya berupa generate node dalam bentuk nilai yakni angka koordinat lokasi dalam suatu waktu. Nilai tersebut dapat baca pada tools Network
Simulator (NS2) untuk digunakan mengukur kinerja pada jaringan.
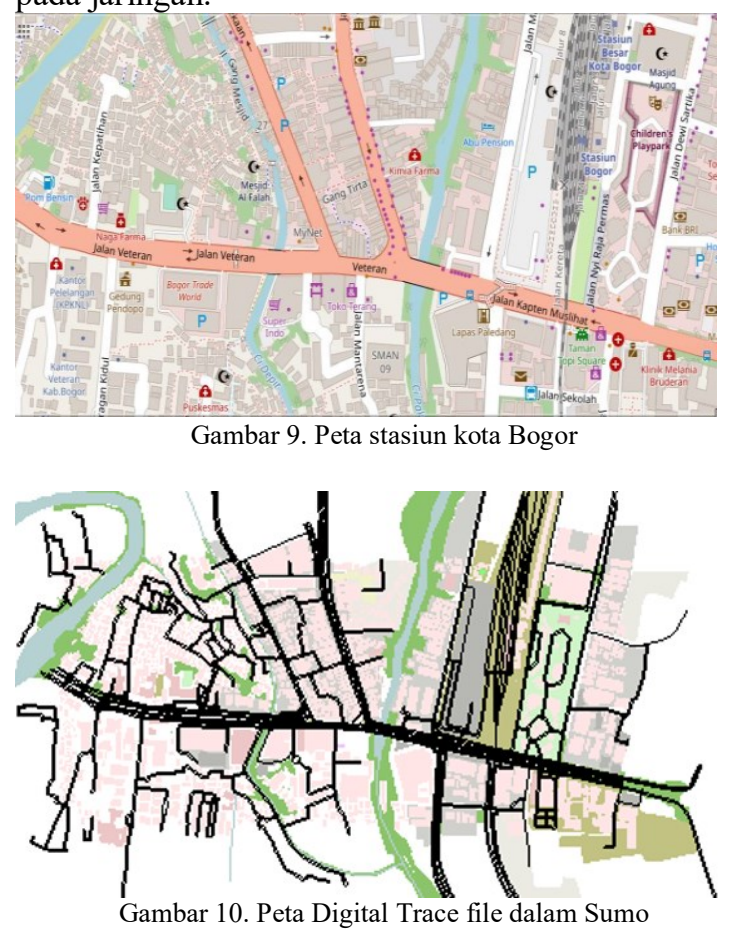

Simulasi menggunakan NS2 dilakukan terhadap protocol routing AODV yakni konsep protocol pertama komunikasi pada VANET (Abedi, et. al., 2009), SDGR protocol routing menggunakan SDN pada VANET, dan SDGR $+\mathrm{R}$ protocol routing yang diusulkan dalam penelitian ini. Parameter simulasi disajikan pada Tabel 1 .

Tabel 1. Simulasi Parameter (Ji, et al., 2016)

\begin{tabular}{cc}
\hline Parameter & Ukuran \\
\hline Area Simulasi & $1500 \mathrm{~m} \times 1500 \mathrm{~m}$ \\
Jumlah Node & $50-100-150-200$ \\
Protokol Kontrol Radio & IEEE $802.11 \mathrm{p}$ \\
Tipe Trafik Jaringan & CBR \\
Ukuran Paket & $512 \mathrm{byte}$ \\
Jarak Komunikasi Transmisi & $200 \mathrm{~m}$ \\
Interval & $0.5-0.75-1$ \\
Mobility Model & SUMO Trace \\
\hline
\end{tabular}

Luas area simulasi berada di antara $1500 \mathrm{~m} \mathrm{x}$ $1500 \mathrm{~m}$ dengan jumlah kendaraan (node) yang diujicoba pada simulasi 50 hingga 200 (Ji, et al., 2016). Node yang bersifat dinamis sehingga topologi selalu berubah oleh sebab itu protokol yang digunakan selama proses pengiriman data pada VANET adalah UDP. Jenis protokol UDP masih menoleransi jika ada segment-segment yang hilang selama proses pengiriman data. Node yang bergerak menghindari retransmisi karena akan mengakibatkan delay jika ternyata ada segment yang hilang. UDP menggunakan tipe trafik jaringan yang dipakai adalah CBR (Constant Bit Rate) yang mewakili trafik realtime dan bit-rate yang tetap. VANET memiliki jarak komunikasi transmisi antara 100 sampai 500 meter, pada percobaan simulasi ini menggunakan $200 \mathrm{~m}$. 


\subsection{Evaluasi Hasil Simulasi}

Pengukuran evaluasi pada kinerja protokol routing diukur dengan persyaratan aplikasi VANET (Indrayana \& Anggoro, 2017). Pada penelitian ini terdapat dua parameter performansi pada jaringan yang akan diukur, yakni PDR (Packet Delivery Ratio) dan latency.

PDR adalah untuk mengukur kemampuan dari jumlah paket yang berhasil berhasil dikirimkan dan diterima. Nilai PDR dinyatakan dalam Persamaan(5):

$P D R=\frac{\text { Data }_{\text {diterima }}}{\text { Data }_{\text {terkirim }}}$

Latency adalah waktu yang dibutuhkan dari node sumber menuju node tujuan. Penundaan ratarata mencirikan latency yang dihasilkan oleh pendekatan routing. Semakin tinggi jeda waktu tersebut maka akan semakin tinggi resiko kegagalan akses. Nilai latency dinyatakan pada Persamaan(6):

Latency $=\frac{\sum_{i=0}^{n} \mathrm{t}_{\text {diterima }}[i]-\mathrm{t}_{\text {terkirim }}[i]}{p k t}$

$i$ adalah indeks paket

$t_{\text {diterima }}$ adalah waktus sampainya paket.

$t_{\text {terkirim }}$ adalah waktu dikirimkan paket.

pkt jumlah total paket yang sampai tujuan.

Evaluasi dilakukan dengan mengukur PDR (Packet Delay Ratio) terhadap jumlah nodes dan latency terhadap jumlah nodes yang telah dihasilkan dengan menggunakan 4 kelompok data uji jumlah nodes masing-masing berjumlah 50, 100, 150 dan 200. Setiap data uji dilakukan uji coba selama $5 \mathrm{kali}$, setelah itu diambil nilai rata-rata nya. Grafik hasil evaluasi pada latency dapat dilihat pada Gambar 11, Gambar 12 dan Gambar 13. Grafik hasil evaluasi pada PDR dapat dilihat pada dan Gambar 14, Gambar 15 dan Gambar 16.

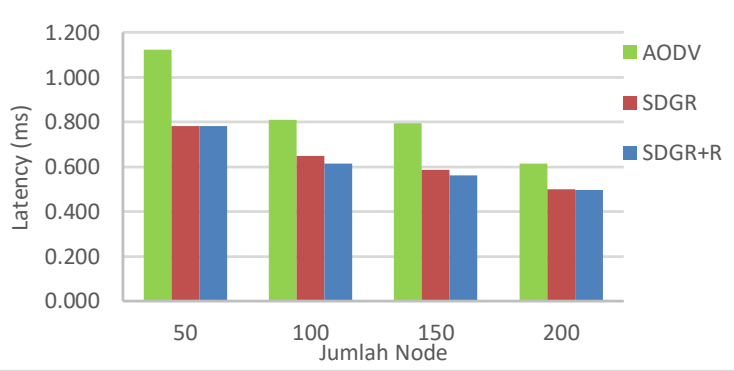

Gambar 11. Kinerja latency terhadap jumlah node pada interval 0.5

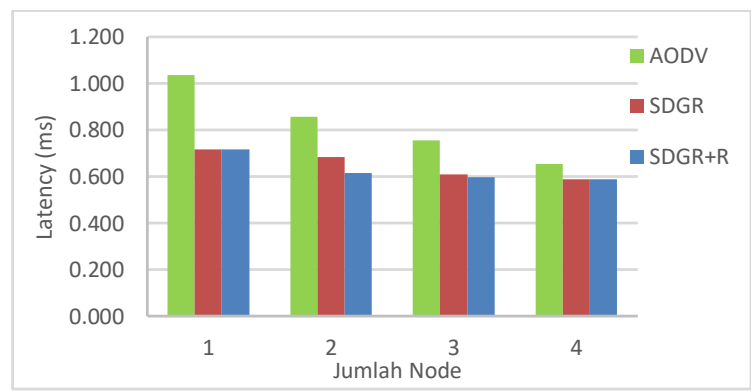

Gambar 12. Kinerja latency terhadap jumlah node pada interval 0,75

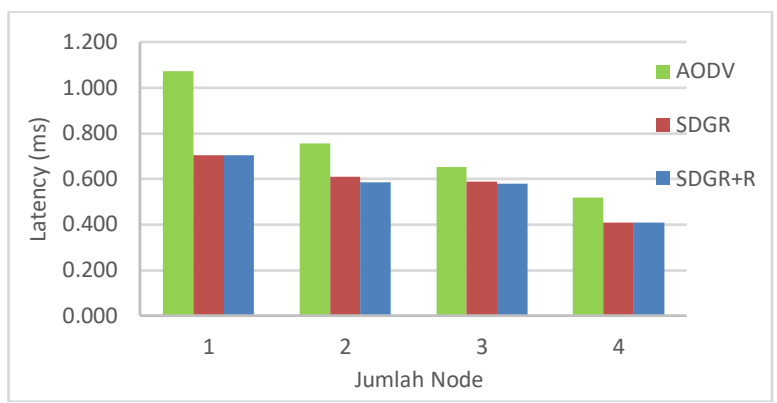

Gambar 13. Kinerja latency terhadap jumlah node pada interval 1

Berdasarkan grafik perbandingan performa, metode SDGR $+\mathrm{R}$ yang diusulkan menghasilkan nilai latency yang lebih baik dari AODV dan SDGR. Nilai latency pada interval 0,5 menunjukkan pada jumlah node 50, SDGR dan SDGR+R memiliki nilai latency yang sama. Pada jumlah node 100, nilai latency pada SDGR + R lebih baik 5,44\% dari SDGR. Pada jumlah node 150 , nilai latency pada $\mathrm{SDGR}+\mathrm{R}$ lebih baik $3,82 \%$ dari SDGR. Pada jumlah node 200, nilai latency pada SDGR lebih baik 0,52\%.

Nilai latency pada interval 0,75 menunjukkan pada jumlah node 50, SDGR dan SDGR+R memiliki nilai latency yang sama. Pada jumlah node 100 , nilai latency pada SDGR $+\mathrm{R}$ lebih baik $4,43 \%$ dari SDGR. Pada jumlah node 150, nilai latency pada SDGR+R lebih baik 1,84\% dari SDGR. Pada jumlah node 200, nilai latency pada SDGR dan SDGR $+\mathrm{R}$ tidak memiliki selisih.

Nilai latency pada interval 1 menunjukkan pada jumlah node 50, SDGR dan SDGR $+\mathrm{R}$ memiliki nilai latency yang sama. Pada jumlah node 100, nilai latency pada SDGR $+\mathrm{R}$ lebih baik $4,40 \%$ dari SDGR. Pada jumlah node 150 , nilai latency pada SDGR+R lebih baik 1,79\% dari SDGR. Pada jumlah node 200, nilai latency pada SDGR lebih baik $0,30 \%$. Nilai ratarata secara keseluruhan SDGR $+\mathrm{R}$ memiliki kinerja latency lebih baik $1.88 \%$.

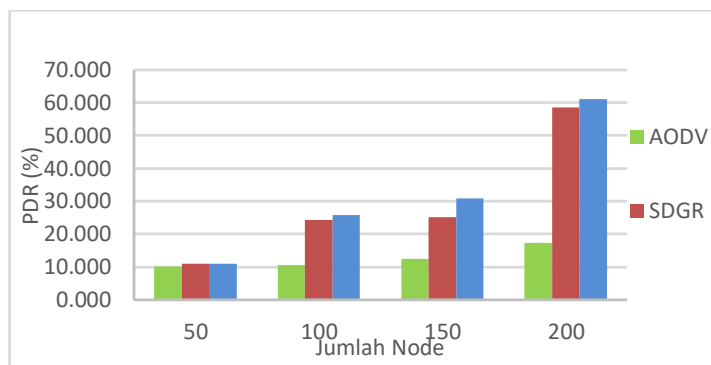

Gambar 14. Kinerja nilai PDR terhadap jumlah node pada interval 0.5

Berdasarkan grafik perbandingan performa, metode $\mathrm{SDGR}+\mathrm{R}$ yang diusulkan menghasilkan nilai PDR yang lebih baik dari AODV dan SDGR. Nilai PDR pada interval 0,5 menunjukkan pada jumlah node 50 , SDGR dan SDGR+R memiliki nilai PDR yang sama. Pada jumlah node 100, nilai PDR pada $\mathrm{SDGR}+\mathrm{R}$ lebih baik $6,53 \%$ dari SDGR. 


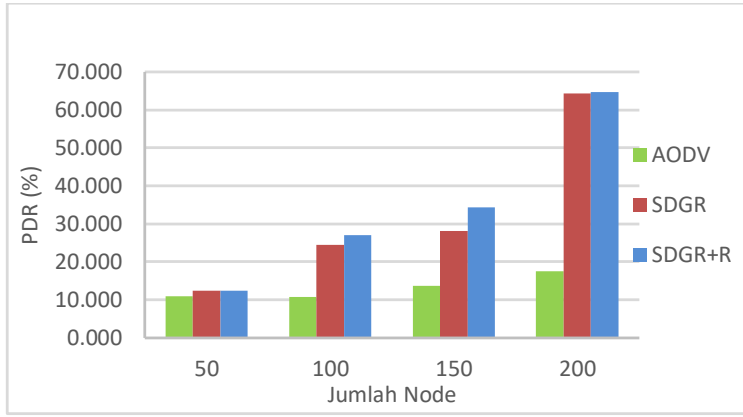

Gambar 15. Kinerja nilai PDR terhadap jumlah node pada interval 0,75

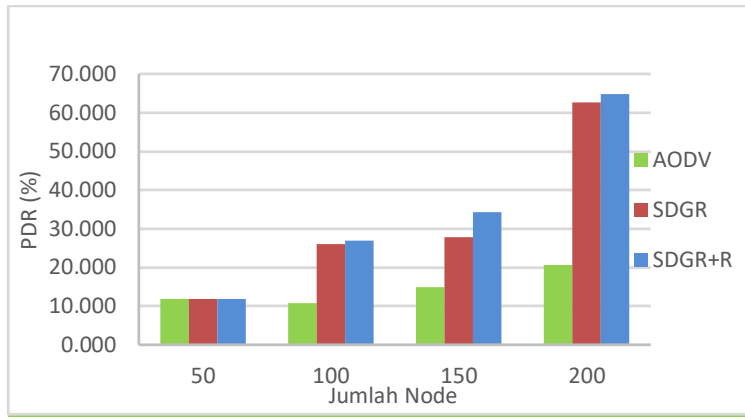

Gambar 16. Kinerja nilai PDR terhadap jumlah node pada interval

Pada jumlah node 150 , nilai PDR pada SDGR + R lebih baik 23,04\% dari SDGR. Pada jumlah node 200, nilai PDR pada SDGR lebih baik 4,32\%.

Nilai PDR pada interval 0,75 menunjukkan pada jumlah node 50, SDGR dan SDGR $+\mathrm{R}$ memiliki nilai PDR yang sama. Pada jumlah node 100 , nilai PDR pada SDGR+R lebih baik 9,92\% dari SDGR. Pada jumlah node 150, nilai PDR pada SDGR $+\mathrm{R}$ lebih baik 22,46\% dari SDGR. Pada jumlah node 200, nilai PDR pada SDGR lebih baik $0,62 \%$.

Nilai pada interval 1 menunjukkan pada jumlah node 50, SDGR dan SDGR $+\mathrm{R}$ memiliki nilai PDR yang sama. Pada jumlah node 100 , nilai PDR pada SDGR + R lebih baik 3,82\% dari SDGR. Pada jumlah node 150 , nilai $\mathrm{PDR}$ pada $\mathrm{SDGR}+\mathrm{R}$ lebih baik 23,36\% dari SDGR. Pada jumlah node 200, nilai PDR pada SDGR lebih baik 3,39\%. Nilai rata-rata secara keseluruhan SDGR+R memiliki kinerja PDR lebih baik $8.12 \%$

Secara umum terlihat dari grafik ketiga algoritma routing protocol menunjukkan semakin banyak jumlah node maka nilai latency akan semakin kecil dan nilai PDR semakin besar. Hal ini dikarenakan semakin banyak node (padat) dalam sebuah jaringan akan semakin kecil kemungkinan link harus reskonstruksi ulang. Daya tahan topology yang lebih stabil mempengaruhi nilai latency maupun PDR yang terkirim oleh node.

Grafik menunjukkan bahwa nilai interval pengiriman paket hanya menghasilkan selisih yang sedikit. Sebagai contoh pada nodes dengan jumlah 100 nilai latency pada Tabel 2 dan nilai PDR pada Tabel 3.
Tabel 2. Latency dengan 100 node (ms)

\begin{tabular}{|c|c|c|c|}
\hline Interval & AODV & SDGR & SDGR + R \\
\hline 0,5 & 0,85594 & 0,68474 & 0,65441 \\
\hline 0,75 & 0,81044 & 0,65025 & 0,61491 \\
\hline 1 & 0,75508 & 0,61102 & 0,58412 \\
\hline
\end{tabular}

Tabel 3. PDR dengan jumlah 100 node (\%)

\begin{tabular}{cccc}
\hline Interval & AODV & SDGR & SDGR+R \\
\hline 0,5 & 10,46 & 24,21 & 25,79 \\
0,75 & 10,76 & 24,51 & 26,94 \\
1 & 10,67 & 25,94 & 26,93
\end{tabular}

Pada Tabel 2 secara rinci diketahui semakin besar nilai interval, semakin kecil nilai latency. Sebagai contoh, pada SDGR $+\mathrm{R}$ dengan interval 0,5 nilai latency nya 0.65441 , interval 0,75 nilai latency 0,61491 dan interval 1 memiliki nilai latency 0,58412. Semakin besar interval, nilai latency semakin berkurang. Pada Tabel 3 secara rinci dapat dilihat bahwa kenaikan nilai interval PDR pada SDGR $+R$ tidak berubah signifikan. Saat interval 0,5 nilai PDR nya $25,79 \%$, saat interval 0,75 nilai PDR nya $26,94 \%$ dan saat interval 1 nilai PDR nya $26,93 \%$. Sehingga perubahan interval tidak terlalu mempengaruhi nilai PDR.

\section{KESIMPULAN DAN SARAN}

\subsection{Kesimpulan}

Penelitian ini mengusulkan SDN-based geographic routing (SDGR) untuk VANET dengan mempertimbangkan arah rute node yang disebut dengan $\mathrm{SDGR}+\mathrm{R}$. Algoritma $\mathrm{SDGR}+\mathrm{R}$ ini diimplementasi berada dalam control plane SDN. Penggunaan $\mathrm{SDGR}+\mathrm{R}$ pada VANET mampu memberikan pandangan kondisi jaringan sehingga dapat memecahkan masalah konektivitas lebih awal jika terdapat kendaraan (node) yang memiliki rute searah.

Kontribusi utama dari penelitian ini dapat diringkas sebagai berikut: (1) Penelitian ini berhasil mengembangkan protocol routing baru yakni $\mathrm{SDGR}+\mathrm{R}$ yang menggunakan metode multicast. Metode multicast ini dapat mengurangi rekonstrusi rute antar node rute sejalur yakni perubahan topology; (2) Hasil simulasi menunjukkan bahwa SDGR+R mencapai kinerja yang lebih baik daripada SDGR dalam hal rasio pengiriman paket (Packet Delivery Ratio) sebesar $8.12 \%$ dan latency sebesar $1.88 \%$. Penambahan pertimbangan arah rute pada konsep SDGR yakni SDGR + R berdampak pada hasil kemampuan protokol perutean (protocol routing) yang lebih baik dibandingkan model SDGR. 


\subsection{Saran}

Beberapa saran yang dapat dilakukan berkenan dengan $\mathrm{SDGR}+\mathrm{R}$ adalah terbukanya peluang penelitian lanjutan, yakni:

1. SDGR dan SDGR+R belum dilakukan uji coba pada fitur Security, misalnya menggunakan metode Rushing, Blackhole dan Jellyfish.

2. Perlu adanya pengujian Efisiensi Powernya pada penggunaan SDN pada VANET baik pada SDGR maupun SDGR $+\mathrm{R}$

3. Pengembangan aplikasi memanfaatkan konsep SDGR $+\mathrm{R}$ pada berbagai bidang, misalnya bidang komersial.

\section{DAFTAR PUSTAKA}

ABEDI, O., BERANGI, R., \& AZGOMI, M. A. 2009. Improving Route Stability and Overhead on AODV: Routing Protocol and Make it Usable for VANET. 464-467. https://doi.org/10.1109/icdcsw.2009.88

DEWI, I. N., MUNADI, R. \& VIDYA Y, L. 2016. Simulasi dan Analisis Performansi Dari Protokol Routing Berbasis Posisi GPRS dan GyTAR untuk Vehicle Communication Pada Vehicular Ad Hoc Network (VANET). Tektrika, Volume 1.

GHAFOOR, H. \& KOO, I. 2018. CR-SDVN: A Cognitive Routing Protocol for SoftwareDefined Vehicular Networks. IEEE Sensors Journal, 18(4), pp. 1761 - 1772.

HE, Z., CAO. J. \& LIU, X. 2016. SDVN: enabling rapid network innovation for heterogeneous vehicular communication. IEEE Network, 30(4), pp. 10-15.

INDRAYANA, K., \& ANGGORO. R. 2017. Studi Kinerja AODV-PNT dengan Weight Factor Dinamis pada Lingkungan VANET. Institut Teknologi Sepuluh November, Surabaya.

JI, X., YU, H., FAN, G., \& FU, W., 2016. SDGR: An SDN-Based Geographic Routing Protocol for VANET. Chengdu, China, IEEE. doi:10.1109/iThings-GreenCOm-CPSComSmartData.2016.70
KADHIM, A, J., \& SENO, S. A. H. 2019. Energyefficient multicast routing protocol based on SDN and fog computing for vehicular networks. Elsevier Ad Hoc Networks, Volume 84, pp. 68-81.

KU, I., LU, Y., GERLA, M., GOMES, R. L., ONGARO, F., \& CERQUEIRA, E. 2014. Towards software-defined VANET: Architecture and services. Ad Hoc Networking Workshop (MED-HOC-NET). IEEE: 10.1109/MedHocNet.2014.6849111

LIN, Y., HUANG, W. \& TANG, Y. 2015. Map-based multi-path routing protocol in VANETs. Xiamen, China, IEEE. doi: 10.1109/ICASID.2015.7405680

LIU, Y. C., CHEN, C. \& CHAKRABORTY, S. 2015. A Software Defined Network architecture for GeoBroadcast in VANETs. London, UK. IEEE. Doi: 10.1109/ICC.2015.7249370

NOORANI, N. \& SENO, S. A. H. 2018. Routing in VANETs Based on Intersection Using SDN and Fog Computing. Mashhad, Iran, IEEE. doi: 10.1109/ICCKE.2018.8566352

PRADANA, P. D., NEGARA, R. M. \& DEWANTA, F. 2017. Evaluasi Performansi Protokol Routing DSR dan AODV Pada Simulasi Jaringan Vehicular Ad-Hoc Network (VANET) Untuk Keselamatan Transportasi Dengan Studi Kasus Mobil Perkotaan. eProceeding of Engineering, Volume 4, pp. 1996-2004.

ZEADALLY, S., HUNT, R., CHEN, Y.-S., IRWIN, A., HASSAN, A. 2012. Vehicular ad hoc networks (VANETS): Status, results, and challenges. Telecommunication Systems, 50(4), pp. 217-241.

ZHU, M., CAO, J., \& PANG, D. 2015. SDN-Based Routing for Efficient Message Propagation in VANET. Qufu, China, $10^{\text {th }}$ International Conference WASA. Springer International Publishing. 2015:788-797 